CLINICAL STUDY

\title{
Lack of regulation of $11 \beta$-hydroxysteroid dehydrogenase type 1 during short-term manipulation of GH in patients with hypopituitarism
}

\author{
Helga A Sigurjonsdottir, Ruth Andrew ${ }^{1}$, Roland H Stimson ${ }^{1}$, Gudmundur Johannsson and Brian R Walker ${ }^{1}$ \\ Department of Endocrinology and Metabolism, Sahlgrenska Academy, Gothenburg University, Sahlgrenska University Hospital, Gröna stråket 8 , \\ 41345 Göteborg, Sweden and ${ }^{1}$ Endocrinology Unit, Queen's Medical Research Institute, Centre for Cardiovascular Science, University of Edinburgh, \\ 47 Little France Cresent, Edinburgh, EH16 4TJ, Scotland, UK \\ (Correspondence should be addressed to H A Sigurjonsdottir; Email: helga.sigurjonsdottir@gu.se)
}

\begin{abstract}
Objective: Evidence from long-term clinical studies measuring urinary steroid ratios, and from in vitro studies, suggests that $\mathrm{GH}$ administered for longer than 2 months down-regulates $11 \beta$-hydroxysteroid dehydrogenase type 1 (11 $\beta$-HSD1), thereby reducing cortisol regeneration in liver and adipose tissue. We aimed to measure acute effects of GH on 11 $\beta$-HSD1 in liver and adipose tissue in vivo, including using a stable isotope tracer.

Design: Observational studies of GH withdrawal and reintroduction in patients with hypopituitarism. Methods: Twelve men with benign pituitary disease causing GH and ACTH deficiency on stable replacement therapy for $>6$ months were studied after $\mathrm{GH}$ withdrawal for 3 weeks, and after either placebo or GH injections were reintroduced for another 3 weeks. We measured cortisol kinetics during $9,11,12,12-{ }^{2} \mathrm{H}_{4}$-cortisol (d4-cortisol) infusion, urinary cortisol/cortisone metabolite ratios, liver $11 \beta$-HSD1 by appearance of plasma cortisol after oral cortisone, and 11ß-HSD1 mRNA levels in subcutaneous adipose biopsies.

Results: GH withdrawal and reintroduction had no effect on 9,12,12-[ $\left.{ }^{2} \mathrm{H}\right]_{3}$-cortisol (d3-cortisol) appearance, urinary cortisol/cortisone metabolite ratios, initial appearance of cortisol after oral cortisone, or adipose 11 $\beta$-HSD1 mRNA. GH withdrawal increased plasma cortisol 30-180 min after oral cortisone, increased d4-cortisol clearance, and decreased relative excretion of $5 \alpha$-reduced cortisol metabolites. Conclusions: In this setting, GH did not regulate 11ß-HSD1 rapidly in vivo in humans. Altered cortisol metabolism with longer term changes in GH may reflect indirect effects on 11 $\beta$-HSD1. These data do not suggest that glucocorticoid replacement doses need to be increased immediately after introducing GH therapy to compensate for reduced $11 \beta$-HSD 1 activity, although dose adjustment may be required in the longer term.
\end{abstract}

European Journal of Endocrinology 161 375-380

\section{Introduction}

$11 \beta$-Hydroxysteroid dehydrogenase type 1 (11ß-HSD1) regenerates cortisol from inactive cortisone in liver and adipose tissue. It has been proposed that $\mathrm{GH}$, via insulinlike growth factor-1 (IGF1), down-regulates 11ß-HSD1 $(1,2$, reviewed in (3)); that increased $11 \beta$-HSD1 in GH-deficient adults may contribute to their central obesity; and that introducing GH treatment in hypopituitary patients may decrease $11 \beta-H S D 1$ and precipitate adrenocortical insufficiency (4) or necessitate an alteration in glucocorticoid replacement $(5,6)$.

A key question is whether changes in 11ß-HSD1 occur acutely after introducing GH therapy. In vitro, IGF1 down-regulates $11 \beta$-HSD1 expression rapidly in adipocytes $(2,7)$ but not in hepatocytes (8). However, in vivo studies in GH-deficient patients have measured $11 \beta$-HSD1 after a minimum of 2 months of therapy $(1,5,6,9-12)$, when indirect effects may affect $11 \beta$-HSD1. In acromegaly $(2,13)$, changes in urinary cortisol metabolite ratios following withdrawal of octreotide occur after 4-8 weeks (2). In obese men, GH effects on 11ß-HSD1 were observed after 6 weeks but resolved after 4-9 months $(14,15)$.

Previous studies of GH effects on 11 $\beta$-HSD1 in vivo have relied almost exclusively on measuring urinary ratios of cortisol/cortisone metabolites; these are influenced by enzymes other than $11 \beta$-HSD1, notably $5 \alpha$ - and $5 \beta$-reductase, and have not been validated in patients receiving glucocorticoid replacement therapy. Although in one study GH administration reduced plasma cortisol after oral cortisone administration (6), commercial use, distribution, and reproduction in any medium, provided the original work is properly cited. 
plasma cortisol was also lower after oral hydrocortisone, suggesting mechanisms in addition to inhibition of $11 \beta$-HSD1. However, in another study, GH reduced $11 \beta$-HSD1 mRNA in adipose tissue (11).

To test the hypothesis that GH/IGF1 regulates $11 \beta$-HSD1 directly and acutely in vivo in human liver and adipose tissue, we studied patients with hypopituitarism during long-term GH therapy, after GH withdrawal for 3 and 6 weeks and after $\mathrm{GH}$ reintroduction for 3 weeks. To quantify the rate of cortisol regeneration by $11 \beta$-HSD1 we used a steady-state tracer infusion with $9,11,12,12-{ }^{2} \mathrm{H}_{4}$-cortisol (d4-cortisol) (16). During d4-cortisol infusion, there is removal of the $11 \alpha^{-2} \mathrm{H}$ by $11 \beta$-HSD type 2 to form 9,12,12$\left[{ }^{2} \mathrm{H}\right]_{3}$-cortisone (d3-cortisone) which is then regenerated to $9,12,12-\left[{ }^{2} \mathrm{H}\right]_{3}$-cortisol (d3-cortisol) by $11 \beta$-HSD1; $\mathrm{d} 4$-cortisol is not regenerated by $11 \beta$-HSD 1 since it is highly unlikely that a deuterium $\left({ }^{2} \mathrm{H}\right)$ will be reintroduced in the $11 \alpha$ position. The dilution of $\mathrm{d} 4$-cortisol by d3-cortisol therefore indicates $11 \beta$-HSD1 reductase activity. We also measured liver 11ß-HSD1 activity (by first pass conversion of orally administered cortisone to cortisol) and adipose 11 $\beta$-HSD1 mRNA (in subcutaneous adipose tissue biopsies).

\section{Subjects and methods}

\section{Patients}

Inclusion criteria: male; hypopituitarism due to benign disease; age 20-75 years; documented GH and ACTH deficiency; stable hormone replacement therapy, including $\mathrm{GH}$ and glucocorticoid for $>6$ months, achieving normal range serum IGF1. Exclusion criteria: acromegaly; anti-inflammatory glucocorticoid therapy by any route within 3 months; significant co-morbidity. Informed consent and local ethical committee approval were obtained.

\section{Protocol}

Participants were randomly allocated to either of the two groups. Six men were studied taking their usual therapy ('baseline'), 3 weeks after withdrawal of GH therapy, and 3 weeks after reintroduction of GH therapy. One man withdrew after completing baseline and some measurements after 3 weeks of GH withdrawal. Another six men were studied at baseline, 3 weeks after withdrawal of GH therapy, and 6 weeks after withdrawal of GH therapy; placebo was administered during weeks 3-6.

Measurements were made during three visits within the final 5 days of each phase. In one visit, a 24-h urine sample was collected; a blood sample was obtained at $0800 \mathrm{~h}$ after overnight fast and usual medication at $0700 \mathrm{~h}$; anthropometric measurements were recorded; dual-energy X-ray absorptiometry was measured for body composition (LUNAR DPX-L scanner, Scanexport Medical, Helsingborg, Sweden); and a $300 \mathrm{mg}$ gluteal subcutaneous adipose biopsy was obtained under local anaesthesia. On a second visit, after overnight fast and omission of morning medication, a single dose of $25 \mathrm{mg}$ cortisone acetate was administered and plasma cortisol measured at intervals for $3 \mathrm{~h}$. On a third visit, after overnight fast and omission of morning medication, d4-cortisol (Cambridge Isotopes, Andover, MA, USA) was infused at $20 \%$ molar percent excess in cortisol at $1.74 \mathrm{mg} / \mathrm{h}$ and blood sampled at intervals for $5 \mathrm{~h}$.

\section{Laboratory assays}

Cortisol and its metabolites (5 $\beta$-tetrahydrocortisol (THF), $5 \alpha$-THF, $5 \beta$-tetrahydrocortisone, cortols, cortolones, and cortisone) were measured in 24-h urine samples by gas chromatography/mass spectrometry as previously described $(17,18)$.

Plasma d4-cortisol, d3-cortisone and d3-cortisol were measured by gas chromatography/mass spectrometry as previously described (18) and tracer kinetics calculated using the mean of up to six measurements in steady state between 225 and 300 min of d4-cortisol infusion. Clearance of d4-cortisol was calculated as (infusion rate)/(concentration). Rate of appearance of d3-cortisol was calculated as (d4-cortisol infusion rate)/(d4-cortisol:d3-cortisol ratio).

RNA was extracted from $100 \mathrm{mg}$ of tissue, oligo dT-primed cDNA synthesised, and transcripts quantified in triplicate using Real-Time PCR with a LightCycler 480 and Mastermix (Roche) and primer-probe sets from Applied Biosystems (Cheshire, UK), as previously described (19). Results are expressed as a ratio of transcript level to the mean of cyclophylin A and 18S.

Plasma cortisol was measured by RIA (ImmunChem, MP Biomedical, High Wycombe, UK), immunoluminetric methods were used to measure serum IGF1 (Nichols Advantage Specialty System, Nichols Institute Diagnostics, San Juan Capistrano, CA, USA) and insulin (ADVIA Centaur Insulin Ready Pack, Bayer Corporation). Enzymatic methods were used to measure plasma glucose (GLU, Roche/Hitachi Roche Diagnostics $\mathrm{GmbH}$ ), free fatty acids (FFA; NEFA C, WAKO Chemicals GmbH, Neuss, Germany) and triglycerides (TG, Roche/ Hitachi Roche Diagnostics $\mathrm{GmbH}$ ).

\section{Statistical analysis}

A power calculation showed that a study of $n=6$ had $85 \%$ power $(n=12$ has $>98 \%$ power $)$ to detect an $18 \%$ change in $\mathrm{d} 3$-cortisol generation in a paired two-tailed test, based on previously published variance of measurement $(16,18)$ and magnitude of effect of $\mathrm{GH}$ on cortisol levels after oral cortisone administration (6). Data are mean \pm s.e.m. Groups were compared at baseline by unpaired Student's t-tests. Effects of GH withdrawal and reintroduction were assessed by oneway repeated measures ANOVA within each group of six patients followed by post hoc paired Student's $t$-tests, if appropriate. Furthermore, the effect of the 3-week 
withdrawal of GH was tested in a combined analysis of 'baseline' and the '3-week withdrawal' data in all 12 patients using paired Student's t-tests. Multiple cortisol measurements after oral cortisone administration were analysed by factorial repeated measures ANOVA, followed by post hoc paired $t$-tests at individual time points, if appropriate; curves were also fitted using Kinetica software (Thermo Scientific, Waltham, MA, USA) to derive an initial appearance rate constant $\left(K_{\mathrm{a}}\right)$.

\section{Results}

Patients had hypopituitarism after removal of benign pituitary adenoma $(n=11)$ or craniopharyngioma $(n=1)$. All patients were receiving substitution therapy with glucocorticoids (10 hydrocortisone, 2 cortisone acetate), thyroxine and testosterone. Five patients were receiving desmopressin. At baseline, the group randomly selected for prolonged GH withdrawal had higher

Table 1 Effects of GH withdrawal and re-introduction.

\begin{tabular}{|c|c|c|c|c|c|c|}
\hline & \multicolumn{3}{|c|}{ Study group 1} & \multicolumn{3}{|c|}{ Study group 2} \\
\hline & Baseline & $\begin{array}{l}3 \text { week } \\
\text { withdrawal }\end{array}$ & $\begin{array}{l}3 \text { week } \\
\text { reintroduction }\end{array}$ & Baseline & $\begin{array}{c}3 \text { week } \\
\text { withdrawal }\end{array}$ & $\begin{array}{c}6 \text { week } \\
\text { withdrawal }\end{array}$ \\
\hline$n$ & 6 & 6 & 5 & 6 & 6 & 6 \\
\hline Age (years) & $64.0 \pm 2.1$ & & & $64.5 \pm 4.8$ & & \\
\hline Height $(\mathrm{cm})$ & $177.4 \pm 3.2$ & & & $178.6 \pm 2.4$ & & \\
\hline $\mathrm{GH}$ dose $(\mathrm{mg} / \mathrm{d})$ & $0.4 \pm 0.2$ & 0 & $0.4 \pm 0.2$ & $0.3 \pm 0.2$ & 0 & 0 \\
\hline IGF1 (ng/ml) & $153.2 \pm 16.0$ & $57.5 \pm 8.7^{\S}$ & $152.4 \pm 19.7^{\natural}$ & $180.5 \pm 28.6$ & $78.2 \pm 15.7^{\ddagger}$ & $72.8 \pm 12.2^{\S}$ \\
\hline Weight (kg) & $89.0 \pm 2.9$ & $88.6 \pm 3.20$ & $88.5 \pm 3.7$ & $102.8 \pm 9.2$ & $102.4 \pm 9.2$ & $102.5 \pm 8.9$ \\
\hline BMI $\left(\mathrm{kg} / \mathrm{m}^{2}\right)$ & $28.5 \pm 1.6$ & $28.5 \pm 1.6$ & $27.2 \pm 1.5$ & $32.2 \pm 2.6$ & $32.3 \pm 2.6$ & $32.0 \pm 2.6$ \\
\hline Waist $(\mathrm{cm})$ & $100.6 \pm 5.2$ & $102.3 \pm 4.7$ & $98.0 \pm 2.8$ & $108.2 \pm 6.1$ & $107.7 \pm 5.5$ & $105.2 \pm 6.2$ \\
\hline $\mathrm{Hip}(\mathrm{cm})$ & $103.8 \pm 1.5$ & $104.4 \pm 1.8$ & $102.8 \pm 0.6$ & $110.2 \pm 4.1$ & $109.8 \pm 3.9$ & $108.4 \pm 4.3$ \\
\hline Waist-to-hip ratio & $0.97 \pm 0.04$ & $0.98 \pm 0.03$ & $0.95 \pm 0.03$ & $0.98 \pm 0.02$ & $0.98 \pm 0.02$ & $0.97 \pm 0.02$ \\
\hline DEXA \% fat & $25.9 \pm 3.6$ & $26.1 \pm 4.1$ & $21.9 \pm 2.1$ & $28.9 \pm 2.7$ & $30.0 \pm 3.2$ & $30.3 \pm 2.6^{\| \prime}$ \\
\hline DEXA lean mass $(\mathrm{kg})$ & $61.8 \pm 2.9$ & $61.5 \pm 3.2$ & $65.2 \pm 3.2$ & $68.3 \pm 4.3$ & $66.0 \pm 3.1$ & $66.5 \pm 3.8$ \\
\hline Systolic BP (mmHg) & $140 \pm 6$ & $145 \pm 7$ & $137 \pm 6$ & $145 \pm 10$ & $142 \pm 8$ & $138 \pm 10$ \\
\hline Diastolic BP (mmHg) & $81 \pm 2$ & $83 \pm 2$ & $80 \pm 3$ & $85 \pm 5$ & $83 \pm 5$ & $81 \pm 5^{\ddagger}$ \\
\hline \multicolumn{7}{|l|}{ Fasting plasma } \\
\hline Glucose (mM) & $4.75 \pm 0.25$ & $4.60 \pm 0.23^{\ddagger}$ & $4.42 \pm 0.24$ & $5.02 \pm 0.30$ & $4.88 \pm 0.53$ & $4.45 \pm 0.21^{\ddagger}$ \\
\hline Insulin (mU/I) & $6.38 \pm 2.55$ & $3.52 \pm 0.48$ & $3.66 \pm 0.49$ & $11.52 \pm 4.01$ & $15.92 \pm 11.29$ & $8.20 \pm 2.58$ \\
\hline $\mathrm{FFA}(\mathrm{mM})$ & $0.51 \pm 0.08$ & $0.40 \pm 0.09$ & $0.37 \pm 0.06$ & $0.59 \pm 0.05$ & $0.40 \pm 0.03^{\ddagger}$ & $0.35 \pm 0.03^{\S}$ \\
\hline Triglycerides (mM) & $0.84 \pm 0.07$ & $0.76 \pm 0.05$ & $0.99 \pm 0.10$ & $2.27 \pm 0.52^{*}$ & $1.90 \pm 0.52$ & $1.77 \pm 0.49^{\S}$ \\
\hline \multicolumn{7}{|l|}{$24 \mathrm{~h}_{\text {urine }}^{\mathrm{b}}$} \\
\hline $\begin{array}{l}\text { Total cortisol } \\
\text { metabolites }(\mathrm{mg} / \mathrm{d})\end{array}$ & $9.84 \pm 3.17$ & $11.10 \pm 2.9$ & $14.2 \pm 2.3$ & $10.3 \pm 1.9$ & $9.5 \pm 0.8$ & $9.5 \pm 1.8$ \\
\hline$(5 \alpha \mathrm{THF}+5 \beta \mathrm{THF}) / \mathrm{THE}$ & $2.33 \pm 0.79$ & $8.07 \pm 2.56$ & $8.08 \pm 3.42$ & $5.55 \pm 2.59$ & $6.34 \pm 2.63$ & $5.20 \pm 3.13$ \\
\hline Cortisol/cortisone & $9.74 \pm 4.65$ & $5.67 \pm 1.42$ & $4.98 \pm 1.02$ & $8.93 \pm 5.77$ & $5.24 \pm 2.20$ & $8.22 \pm 3.36$ \\
\hline $5 \alpha \mathrm{THF} / 5 \beta \mathrm{THF}$ & $1.06 \pm 0.11$ & $1.02 \pm 0.12$ & $1.15 \pm 0.09$ & $1.62 \pm 0.29$ & $1.47 \pm 0.18$ & $1.20 \pm 0.33$ \\
\hline $5 \alpha \mathrm{THF} /$ cortisol & $8.03 \pm 1.39$ & $9.41 \pm 1.72$ & $9.57 \pm 0.69$ & $11.73 \pm 1.67$ & $11.48 \pm 2.19$ & $8.87 \pm 2.31^{\ddagger}$ \\
\hline $5 \beta$ THF/cortisol & $7.82 \pm 1.39$ & $9.09 \pm 1.16$ & $8.24 \pm 0.74$ & $7.73 \pm 1.13$ & $8.56 \pm 1.94$ & $8.35 \pm 1.43$ \\
\hline \multicolumn{7}{|l|}{$\mathrm{d} 4$-Cortisol tracer kinetics } \\
\hline $\begin{array}{l}\text { d4-Cortisol } \\
\text { clearance }(1 / \min )\end{array}$ & $0.73 \pm 0.29$ & $1.93 \pm 1.37$ & $0.79 \pm 0.22$ & $0.65 \pm 0.14$ & $0.66 \pm 0.16$ & $0.86 \pm 0.21^{\ddagger}$ \\
\hline $\begin{array}{l}\text { Ra d3-cortisol } \\
\text { (nmol/min) }\end{array}$ & $15.3 \pm 1.0$ & $16.1 \pm 2.5$ & $13.4 \pm 0.9$ & $6.5 \pm 0.9^{\dagger}$ & $7.4 \pm 1.4$ & $6.8 \pm 1.1$ \\
\hline \multicolumn{7}{|c|}{ Plasma cortisol after oral cortisone } \\
\hline $\begin{array}{l}\text { Appearance rate } \\
\text { constant }\left(K_{\mathrm{a}} \text {, per min) }\right.\end{array}$ & $0.074 \pm 0.019$ & $0.031 \pm 0.008$ & $0.046 \pm 0.014$ & $0.061 \pm 0.031$ & $0.041 \pm 0.012$ & $0.073 \pm 0.024$ \\
\hline \multicolumn{7}{|l|}{ Adipose mRNA } \\
\hline $11 \beta-H S D 1$ & $0.55 \pm 0.09$ & $0.65 \pm 0.17$ & $0.65 \pm 0.20$ & $0.69 \pm 0.14$ & $0.64 \pm 0.14$ & $0.79 \pm 0.25$ \\
\hline $\begin{array}{l}\text { Hexose-6-phosphate } \\
\text { dehydrogenase }\end{array}$ & $0.75 \pm 0.07$ & $0.73 \pm 0.08$ & $0.59 \pm 0.03$ & $0.71 \pm 0.09$ & $0.78 \pm 0.07$ & $0.69 \pm 0.09$ \\
\hline $\mathrm{GR} \alpha$ & $0.80 \pm 0.08$ & $0.77 \pm 0.09$ & $0.74 \pm 0.05$ & $0.83 \pm 0.09$ & $0.73 \pm 0.07$ & $0.86 \pm 0.09$ \\
\hline $5 \alpha$-Reductase 1 & $0.94 \pm 0.10$ & $1.12 \pm 0.15$ & $1.23 \pm 0.34$ & $1.00 \pm 0.07$ & $0.92 \pm 0.13$ & $1.18 \pm 0.17$ \\
\hline
\end{tabular}

${ }^{\star} P<0.05,{ }^{\dagger} P<0.01$ for differences between study groups at baseline; ${ }^{\ddagger} P<0.05,{ }^{\S} P<0.01$, " $P<0.001$ for effects of GH withdrawal (i.e. differences from baseline) within each study group; ${ }^{\circledR} P<0.01$ for effects of $\mathrm{GH}$ reintroduction (i.e. differences from 3 week withdrawal) in study group 1 . BMI, body mass index; $\mathrm{BP}$, blood pressure; FFA, free fatty acids; Ra, rate of appearance; GR, glucocorticoid receptor.

${ }^{a}$ Note that one subject withdrew from the GH reintroduction group, so that mean data may appear to differ from values after 3 weeks withdrawal, but only statistically significant differences are highlighted.

${ }^{\mathrm{b}}$ Total cortisol excretion was calculated from the sum of $5 \beta$-THF, $5 \alpha$-THF and THE. The balance between $11 \beta$-HSD activities in all tissues was assessed as the ratio of $(5 \beta$-THF $+5 \alpha$-THF)/THE. Renal $11 \beta$-HSD type 2 activity was assessed as urinary cortisol/cortisone ratio. The balance of $5 \alpha$ - and $5 \beta$-reductases was assessed by the ratio $5 \beta$-THF/ $5 \alpha$-THF. $5 \alpha$ - and $5 \beta$-reduction of cortisol was also assessed by $5 \alpha$-THF/cortisol and $5 \beta$-THF/cortisol ratios. 
fasting plasma triglycerides and tended to have higher body mass index, \% body fat and fasting insulin levels than the group selected for GH withdrawal followed by reintroduction (Table 1 ).

Withdrawal of GH resulted in a substantial fall in IGF1 after 3 weeks which was sustained after 6 weeks. Reintroduction of GH restored IGF1 to baseline values within 3 weeks (Table 1). Withdrawal of GH after 3 weeks also reduced fasting plasma FFA (in all 12 participants, from $0.55 \pm 0.05$ to $0.40 \pm 0.04 \mathrm{mM}$, $P=0.02$ ) and triglycerides (in all 12 , from $1.55 \pm 0.33$ to $1.32 \pm 0.30 \mathrm{mM}, P=0.04$ ), which were lower after 6 weeks of GH withdrawal (Table 1). Reintroduction of $\mathrm{GH}$ prevented this decline in triglycerides. After 6 weeks of GH withdrawal the percentage of body fat increased and diastolic blood pressure decreased, but there were no other measured changes in glucose/insulin homeostasis or body composition.

With exogenous glucocorticoid therapy, urinary cortisol metabolite excretion was highly variable (Table 1). There were no differences between groups in indices of overall $11 \beta$-HSD activity or renal $11 \beta-H S D 2$ activity. However, the ratio of $5 \alpha-\mathrm{THF} /$ cortisol, which reflects $5 \alpha$-reductase activity in the liver, was decreased after 6 weeks GH withdrawal; the reintroduction of $\mathrm{GH}$ prevented this decline.

Kinetics of d4- and d3-cortisol is shown in Table 1 and Fig. 1A. By chance, d3-cortisol generation rate was higher at baseline in the group randomised to $\mathrm{GH}$ reintroduction. The d4-cortisol clearance increased after 6 weeks of $\mathrm{GH}$ withdrawal. The d3-cortisol regeneration rate was not affected by $\mathrm{GH}$ withdrawal or reintroduction in either group or when all 12 participants were included.

Cortisol levels following oral cortisone were higher after 3 weeks of GH withdrawal among all participants (Fig. 1B), and tended to rise further after 6 weeks GH withdrawal and revert to baseline values on reintroduction of GH. However, these changes occurred between 30 and $180 \mathrm{~min}$ and did not reflect the initial rate of appearance of cortisol $<25 \mathrm{~min}$ after cortisone administration.

Adipose mRNA transcripts for 11ß-HSD1 were unaffected by $\mathrm{GH}$ withdrawal or reintroduction (Table 1). Similarly, there were no changes in transcript levels of other genes thought to influence glucocorticoid signalling in adipose tissue: hexose-6-phosphate dehydrogenase, GR $\alpha$ and $5 \alpha$-reductase type 1 .

\section{Discussion}

This is the first study to dissect acute effects of GH on $11 \beta$-HSD1 using specific in vivo assays in humans. It shows that in men with hypopituitarism, withdrawal of $\mathrm{GH}$ for up to 6 weeks, or reintroduction of $\mathrm{GH}$ for 3 weeks, has no effect on 11 $\beta$-HSD1 in the whole
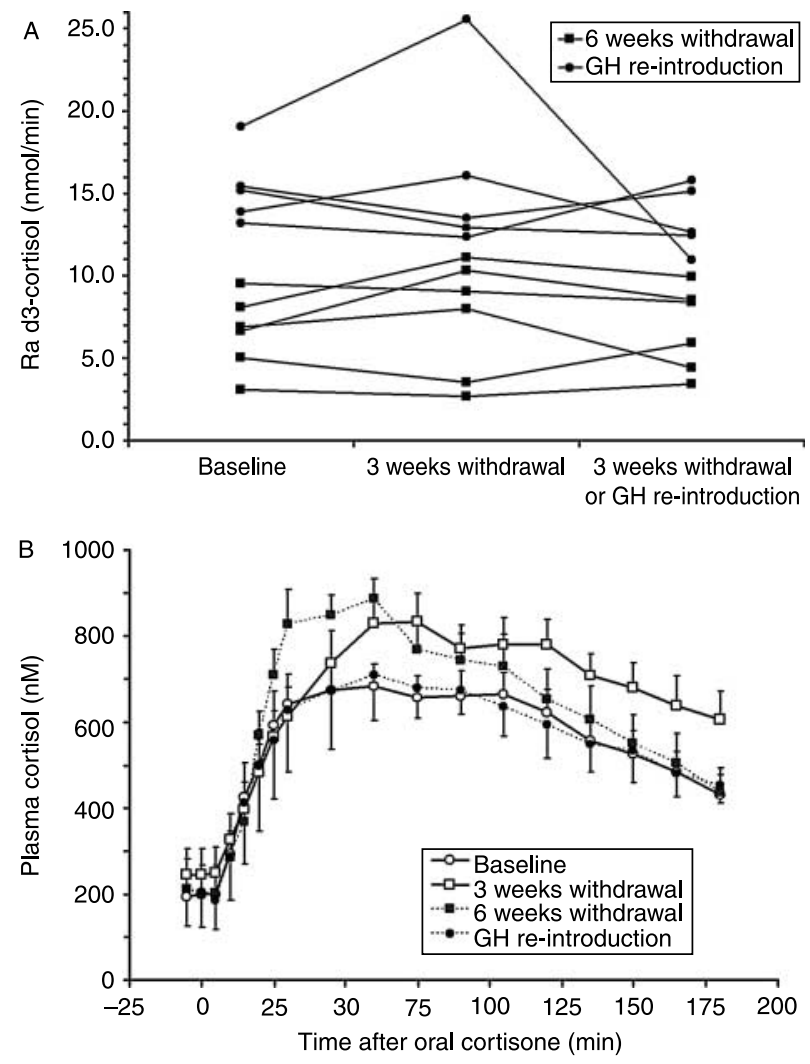

Figure 1 Effects of GH withdrawal and re-introduction on $11 \beta-H S D 1$ conversion of cortisone to cortisol. (A) Rate of appearance (Ra) of d3-cortisol during steady-state d4-cortisol infusion. Results are shown for individual patients allocated to 6 weeks GH withdrawal (squares) or GH withdrawal and reintroduction (circles). Summary statistics are shown in Table 1. Results varied widely among patients with hypopituitarism but by chance, Ra of d3-cortisol was higher in the group allocated with $\mathrm{GH}$ reintroduction. However, there were no significant changes in $\mathrm{Ra}$ of d3-cortisol on $\mathrm{GH}$ withdrawal for 3 or 6 weeks, or on GH reintroduction for 3 weeks. (B) First pass conversion of cortisone to cortisol in liver. Results show mean \pm S.E.M. plasma cortisol concentrations after oral administration of cortisone acetate $25 \mathrm{mg}$ at time $=0$. Results were compared by repeated measures ANOVA and post hoc paired Student's $t$-tests, if appropriate. In all participants $(n=12)$, there was a difference between baseline (open circle, solid line) and 3 weeks of $\mathrm{GH}$ withdrawal (open squares, solid lines; $P<0.03$; post hoc tests significant at time $=150$ and 180 ). There was no additional significant change in plasma cortisol after 6 weeks GH withdrawal ( $n=6$; filled squares, dotted lines). However, cortisol values were reduced by reintroduction of $\mathrm{GH}$ treatment $(n=6$; filled circles, dotted lines; $P<0.02$ by ANOVA, no single time-points significant in post hoc tests). Curves from each individual were fitted with Kinetica software: the appearance rate constants $\left(K_{\mathrm{a}}\right)$ are shown in Table 1 and did not differ between groups.

body (d3-cortisol appearance rate and urinary cortisol/ cortisone metabolite ratios), in liver (initial rate of cortisol appearance following oral cortisone) or in subcutaneous adipose tissue (transcript levels). These findings do not support the inference from previous long-term studies that GH acts through IGF1 directly to suppress 11ß-HSD1 (3). 
GH withdrawal increased plasma cortisol concentrations for 30-180 min after oral cortisone, but the lack of change in total urinary cortisol metabolite excretion suggests that the consequences for cortisol bioavailability are minor. It appears that the elevated plasma cortisol depends on factors other than $11 \beta$-HSD1 activity, since the initial rate of cortisol appearance was unaltered, and there was no associated change in $\mathrm{d} 3$-cortisol generation. $5 \alpha$-Reductase activity (assessed by urinary $5 \alpha$-THF/cortisol ratio) decreased, and $\mathrm{d} 4$-cortisol clearance paradoxically increased, on prolonged GH withdrawal, suggesting that GH affects other cortisol-metabolising enzymes. Alternatively, GH may influence gastric emptying (20).

$\mathrm{GH}$ withdrawal for 6 weeks was associated with a fall in plasma FFA and triglycerides and modest increase in body fat content without measurable changes in glucose/insulin homeostasis. This occurred in the absence of changes in 11 1 -HSD1, making it less likely that $\mathrm{GH}$ effects on $11 \beta$-HSD1 are a primary mediator of abnormal body composition in GH deficiency. Changes in $11 \beta$-HSD1 mRNA in adipose tissue (11) with prolonged GH therapy may reflect indirect effects; although these might perhaps be mediated by alterations in body composition and insulin signalling, as we have described in subjects receiving PPAR $\gamma$ agonists (19), previous studies have not associated changes in urinary cortisol/cortisone metabolite ratios with changes in insulin sensitivity or body fat content $(9,10)$.

The strength of these studies lies in the detailed assessment of cortisol metabolism and the paired analyses of 12 patients, which is a comparable sample size to that used in most previous studies in this area, and which we calculated gives ample statistical power to detect differences of the magnitude observed in previous studies. Weaknesses include: the fact that this group of patients had been exposed to chronic GH therapy in advance of the study, and GH was only deficient for 3 weeks, so that effects of GH (re)introduction may have been underestimated; the sample size was small for the subgroups at 6 weeks ( $n=6$ and 5 per group); and the chance differences at baseline between these groups, e.g. in d3-cortisol generation and plasma triglycerides. As a result, direct comparisons at week 6 between subjects with and without $\mathrm{GH}$ reintroduction were avoided. The d4-cortisol tracer has been used extensively in healthy volunteers, but not in patients with glucocorticoid deficiency; we elected to limit our analysis to results which are entirely derived from the exogenous deuterated tracer infusion, and have not described the more variable results for endogenous cortisol production and metabolism.

Extrapolation from small exploratory studies must always be cautious, but an important clinical implication of these findings is that these data do not support the concept that the dose of glucocorticoid replacement therapy needs to be adjusted upwards in the short-term following introduction of $\mathrm{GH}$ to compensate for a fall in
11 $\beta$-HSD1 activity. Although glucocorticoid dosing should be reassessed after medium to long-term GH therapy, further studies are required to clarify the need for dose adjustment in the short term.

\section{Declaration of interest}

B R Walker is an inventor on patents owned by the University of Edinburgh relating to $11 \beta$-HSD1 inhibitors. The other authors have no conflicts of interest to declare.

\section{Funding}

This work was supported by the British Heart Foundation and University of Gothenburg.

\section{Acknowledgements}

We are grateful to Alison Rutter, Anna-Lena Jonsson and Ingrid Hansson and the staff of the Wellcome Trust Clinical Research Facility Mass Spectrometry Core Laboratory in Edinburgh for technical assistance. GH and placebo were kindly provided by NovoNordisk.

\section{References}

1 Weaver JU, Thaventhiran L, Noonan K, Burrin JM, Taylor NF, Norman MR \& Monson JP. The effect of growth hormone replacement on cortisol metabolism and glucocorticoid sensitivity in hypopituitary adults. Clinical Endocrinology 1994 41 639-648.

2 Moore JS, Monson JP, Kaltsas G, Putignano P, Wood PJ, Sheppard MC, Besser GM, Taylor NF \& Stewart PM. Modulation of $11 \beta$ hydroxysteroid dehydrogenase isozymes by growth hormone and insulin-like growth factor: in vivo and in vitro studies. Journal of Clinical Endocrinology and Metabolism $1999844172-4177$.

3 Agha A \& Monson JP. Modulation of glucocorticoid metabolism by the growth hormone-IGF-1 axis. Clinical Endocrinology $2007 \mathbf{6 6}$ 459-465.

4 Giavoli C, Libe R, Corbetta S, Ferrante E, Lania A, Arosio M, Spada A \& Beck-Peccoz P. Effect of recombinant human growth hormone $(\mathrm{GH})$ replacement on the hypothalamic-pituitaryadrenal axis in adult GH-deficient patients. Journal of Clinical Endocrinology and Metabolism 200489 5397-5401.

5 Gelding SV, Taylor NF, Wood PJ, Noonan K, Weaver JU, Wood DF \& Monson JP. The effect of growth hormone replacement therapy on cortisol-cortisone interconversion in hypopituitary adults: evidence for growth hormone modulation of extrarenal $11 \beta$ hydroxysteroid dehydrogenase activity. Clinical Endocrinology 1998 48 153-162.

6 Swords FM, Carroll PV, Kisalu J, Wood PJ, Taylor NF \& Monson JP. The effects of growth hormone deficiency and replacement on glucocorticoid exposure in hypopituitary patients on cortisone acetate and hydrocortisone replacement. Clinical Endocrinology $200359613-620$.

7 Tomlinson JW, Moore J, Cooper MS, Bujalska I, Shahmanesh M, Burt C, Strain A, Hewison M \& Stewart PM. Regulation of expression of $11 \beta$-hydroxysteroid dehydrogenase type 1 in adipose tissue: tissue-specific induction by cytokines. Endocrinology 2001 142 1982-1989.

8 Ricketts ML, Shoesmith KJ, Hewison M, Strain A, Eggo MC \& Stewart PM. Regulation of $11 \beta$-hydroxysteroid dehydrogenase type 1 in primary cultures of rat and human hepatocytes. Journal of Endocrinology 1998156 159-168.

9 Frajese GV, Taylor NF, Jenkins PJ, Besser GM \& Monson JP. Modulation of cortisol metabolism during treatment of acromegaly is independent of body composition and insulin sensitivity. Hormone Research 200461 246-251. 
10 Toogood AA, Taylor NF, Shalet SM \& Monson JP. Modulation of cortisol metabolism by low-dose growth hormone replacement in elderly hypopituitary patients. Journal of Clinical Endocrinology and Metabolism 200085 1727-1730.

11 Paulsen SK, Pedersen SB, Jorgensen JO, Fisker S, Christiansen JS, Flyvbjerg A \& Richelsen B. Growth hormone (GH) substitution in GH-deficient patients inhibits $11 \beta$-hydroxysteroid dehydrogenase type 1 messenger ribonucleic acid expression in adipose tissue. Journal of Clinical Endocrinology and Metabolism 200691 1093-1098.

12 Walker BR, Andrew R, MacLeod KM \& Padfield PL. Growth hormone replacement inhibits renal and hepatic 11ß-hydroxysteroid dehydrogenases in ACTH-deficient patients. Clinical Endocrinology 199849 257-263.

13 Trainer PJ, Drake WM, Perry LA, Taylor NF, Besser GM \& Monson JP. Modulation of cortisol metabolism by the growth hormone receptor antagonist pegvisomant in patients with acromegaly. Journal of Clinical Endocrinology and Metabolism 200186 2989-2992.

14 Sigurjonsdottir HA, Koranyi J, Axelson M, Bengtsson BA \& Johannsson G. GH effect on enzyme activity of 11ßHSD in abdominal obesity is dependent on treatment duration. European Journal of Endocrinology $2006 \mathbf{1 5 4} 69-74$.

15 Tomlinson JW, Crabtree N, Clark PMS, Holder G, Toogood AA, Shackleton CHL \& Stewart PM. Low-dose growth hormone inhibits 11ß-hydroxysteroid dehydrogenase type 1 but has no effect upon fat mass in patients with simple obesity. Journal of Clinical Endocrinology and Metabolism 200388 2113-2118.
16 Andrew R, Smith K, Jones GC \& Walker BR. Distinguishing the activities of 11ß-hydroxysteroid dehydrogenases in vivo using isotopically labelled cortisol. Journal of Clinical Endocrinology and Metabolism 200287 277-285.

17 Best R \& Walker BR. Additional value of measurement of urinary cortisone and unconjugated cortisol metabolites in assessing the activity of $11 \beta$-hydroxysteroid dehydrogenase in vivo. Clinical Endocrinology 199747 231-236.

18 Andrew R, Westerbacka J, Wahren J, Yki-Jarvinen H \& Walker BR. The contribution of visceral adipose tissue to splanchnic cortisol production in healthy humans. Diabetes 200554 1364-1370.

19 Wake DJ, Stimson RH, Tan GD, Homer NZ, Andrew R, Karpe F \& Walker BR. Effects of peroxisome proliferator-activated receptor-alpha and -gamma agonists on 11beta-hydroxysteroid dehydrogenase type 1 in subcutaneous adipose tissue in men. Journal of Clinical Endocrinology and Metabolism 200792 1848-1856.

20 Scolapio JS, Camilleri M, Fleming CR, Oenning LV, Burton DD, Sebo TJ, Batts KP \& Kelly DG. Effect of growth hormone, glutamine, and diet on adaptation in short-bowel syndrome: a randomized, controlled study. Gastroenterology 1997113 1074-1081.

Received 5 June 2009

Accepted 17 June 2009 